\title{
Utilização de Recursos de Tecnologia Assistiva por Escolares com Deficiência Visual
}

\section{Use of Assistive Technology Resources for Students with Visual Impairment}

Resumo: Considerando a tecnologia assistiva uma área de característica interdisciplinar, esta publicação visa apresentar como a Pedagogia e a Terapia Ocupacional propiciaram ações de reabilitação entre escolares com deficiência visual, visando identificar o uso de recursos de tecnologia assistiva. Foi realizada pesquisa quantitativa e qualitativa entre escolares com deficiência visual participantes de Programas de Reabilitação do CEPRE/FCM/UNICAMP e que estavam incluidos em escolas regulares. A coleta de dados foi realizada em 2010 por meio de um diário de campo e questionário semi-estruturado aplicado por meio de entrevista. Foram investigadas as variáveis: idade, sexo, acuidade visual, visão residual, tecnologia assistiva, informática acessível e interação grupal. A população foi composta por 46 escolares. No setor de Pedagogia $54,0 \%$ dos escolares declararam utilizar recursos ópticos, $46,0 \%$ recursos não ópticos e $38,4 \%$ a informática, mas desconheciam os softwares específicos. Na Terapia Ocupacional $70,0 \%$ dos escolares desconheciam os recursos de tecnologia assistiva e relataram ausencia destes na escola. Verificou-se que a utilização de recursos de tecnologia assistiva por escolares foi propiciada pelos Programas de Reabilitação e que esses recursos ainda não estão presentes na escola.

Palavras-chave: Tecnologia Assistiva. Cegueira. Baixa visão. Pedagogia. Terapia Ocupacional.

Abstract: Considering the area of assistive technology an interdisciplinary character, this paper presents results of a research showing how the sectors of Pedagogy and Occupational Therapy of Rehabilitation Programs in CEPRE/FCM/UNICAMP have acted in order to help students with visual impairment in the use of assistive technology resources. It is a quantitative and qualitative research, that was conducted with visually impaired students participating of the Rehabilitation Programs CE$\mathrm{PRE} / \mathrm{FCM} / \mathrm{UNICAMP}$ and that were included in regular schools. Data collection was conducted in 2010 through a field diary and semi-structured questionnaire applied by interview. The variables considered were: age, sex, visual acuity, residual vision, assistive technology and group interaction. The population was composed of 46 students. In the sector of Pedagogy $54.0 \%$ of students reported used optical devices, $46.0 \%$ non-optical resources and $38.4 \%$ computing, but were unaware of the specific software. In Occupational Therapy sector, $70.0 \%$ of students were unaware of the resources of assistive technology and reported absence of these resources in the school. It was found that Rehabilitation Programs offered the use of assistive technology resources for students and that these features are still missing in school.

Keywords: Assistive technology. Blindness. Low vision. Pedagogy. Occupational therapy.

GASPARETTO, Maria Elisabete Rodrigues Freire. et al. Utilizacão de Recursos de Tecnologia Assistiva por Escolares com Deficiência Visual. I nformática na Educação: teoria e prática, Porto Alegre, v. 15, n. 2, p. 113-130, jul./dez. 2012.

\section{Maria Elisabete Rodrigues Freire Gasparetto} Rita de Cassia letto Montilha Sonia Maria Chadi de Paula Arruda Jaqueline Sperque Tássia Lopes de Azevedo Maria Inês Rubo de Souza Nobre

Universidade Estadual de Campinas

\section{I ntrodução}

$\square$ sta publicação visa apresentar como os setores de Pedagogia e de Terapia Ocupacional dos Programas I nfantil e de Adolescentes com Deficiência Visual do Centro de Estudos e Pesquisas em Reabilitação Prof. Dr. Gabriel Porto da Faculdade de Ciências Médicas da Universidade Estadual de Campinas (CEPRE/FCM/UNICAMP) têm proporcionado aos escolares com deficiência visual a utilização de Recursos de Tecnologia Assistiva para melhorar o desempenho nas atividades coti- 
dianas e como facilitadores da inclusão educacional e social.

A inclusão da pessoa com deficiência no ensino regular é um discurso que está muito distante das práticas na área da educação (CAIADO, 2003). Para que esta inclusão ocorra é fundamental a atuação do educador, que necessita conhecer as necessidades do aluno e prover formas para que as práticas convertam para um ensino diferente para todos, em que os alunos tenham condições de aprender, segundo suas próprias capacidades (ROPOLI et al., 2010, p. 15). Para Vygostky (2003), a criança com deficiência se desenvolve de forma distinta e tal afirmação implica que o educador conheça as especificidades da deficiência para poder construir o caminho no qual a criança será conduzida.

A educação de pessoas com deficiência está fundamentada na Declaração dos Direitos do Homem (LIMA, 2007) e nas declarações da UNESCO (1994) sobre a Declaração de Salamanca propondo que o princípio da inclusão caminhe rumo à escola para todos - um lugar que inclua todos os alunos, celebre a diferença, apoie a aprendizagem e responda às necessidades individuais. Neste princípio todas as pessoas devem aprender juntas, sempre que isso for possível, não importando as diferenças ou dificuldades que elas possam ter.

A Declaração de Salamanca prevê, ainda que, as pessoas com deficiência devam ter acesso à escola regular que deverá incluí-las dentro de uma pedagogia centrada na criança, capaz de atender as suas necessidades (UNESCO, 1994). Aos jovens e adultos que não conseguem completar a educação básica em idade apropriada é propiciado que frequentem a Educação para Jovens e Adultos (EJA), uma forma de ensino da rede pública no Brasil que visa oferecer o ensino fundamental e médio com qualidade para as pessoas que não possuem idade escolar (BRASIL, 2009).

\section{Dados da Deficiência Visual}

Com base nos resultados do Censo Demográfico de 2010, os dados do Instituto Brasileiro de Geografia e Estatística (IBGE, 2010) evidenciam que há no Brasil, 45,6 milhões de pessoas com algum tipo de deficiência, o que corresponde a $23,91 \%$ da população brasileira. Deste total, 12,7 milhões $(6,7 \%$ da população total) possuem pelo menos um tipo de deficiência grave sendo que a deficiência visual grave foi a que prevaleceu na população, acometendo 3,5\% da população (IBGE, 2010).

Conforme Decreto 5.296 de 02 de dezembro de 2004, a deficiência visual abrange a baixa visão e a cegueira e as define considerando que uma pessoa apresenta baixa visão quando a acuidade visual do melhor olho com a melhor correção óptica situa-se, entre $0,3(20 / 60)$ a $0,05(20 / 400)$ e/ou também nos casos em que a somatória da medida do campo visual em ambos os olhos for igual ou menor que $60^{\circ}$. É considerada como cega, a pessoa que apresenta acuidade visual igual ou menor a 0,05 (20/400) no melhor olho com a melhor correção óptica (LIMA, 2007). Sobre esta definição cabe reiterar que estão sendo designadas como cegas, as pessoas que podem possuir resíduo visual para a realização de tarefas cotidianas.

Segundo a Organização Mundial de Saúde a baixa visão pode ser subdividida em: mode- 
rada, situação em que o indivíduo apresenta acuidade visual entre $20 / 60(0,3)$ e $>20 / 200$ $(0,1)$; grave, entre $20 / 200(0,1)$ e $>20 / 400$ $(0,05)$ e profunda, entre 20/400 $(0,05)$ e $>20 / 1200(0,01)$ no melhor olho com meIhor correção. Nesta classificação, cegueira é subdividida em próximo à cegueira com acuidade visual entre $20 / 1200(0,02)$ e 20/2500 $(0,008)$ e cegueira total no qual o indivíduo não possui percepção luminosa (ORGANIZAÇÃO MUNDIAL DA SAÚDE, 1993).

As pessoas com deficiência visual necessitam conhecer estratégias, recursos e equipamentos que facilitem o aprendizado das atividades diárias e de leitura e escrita. É papel do oftalmologista e da equipe interdisciplinar de habilitação e reabilitação favorecer este conhecimento. Atualmente todo este processo é denominado Tecnologia Assistiva. O desempenho das pessoas com deficiência visual pode ser potencializado por meio desses recursos.

O Decreto no 7.612, de 17 de novembro de 2011, criou o Plano Nacional dos Direitos da Pessoa com Deficiência - Plano Viver sem Limite, que garante um sistema educacional inclusivo, a ampliação e qualificação da rede de atenção à saúde da pessoa com deficiência, em especial os serviços de habilitação e reabilitação e promoção do acesso, do desenvolvimento e da inovação em tecnologia assistiva (BRASIL, 2011).

\section{Recursos de Tecnologia Assistiva}

Para elaboração de um conceito de tecnologia assistiva que pudesse subsidiar as políticas públicas brasileiras, os membros do Co- mitê de Ajudas Técnicas (CAT), da Secretaria Especial dos Direitos Humanos da Presidência da República, realizaram uma profunda revisão no referencial teórico nacional e internacional, pesquisando os termos Tecnologia Assistiva, Tecnologia de Apoio, Ajudas Técnicas, Ayudas Tecnicas, Assistive Technology e Adaptive Technology (BRASIL, 2009).

A partir desta pesquisa e outros referenciais o CAT aprovou, em 14 de dezembro de 2007, o seguinte conceito:

Tecnologia Assistiva é uma área do conhecimento, de característica interdisciplinar que engloba produtos, recursos, metodologia, estratégias, práticas e serviços que objetivam promover a funcionalidade, relacionada à atividade e participação, de pessoas com deficiência, incapacidades ou mobilidade reduzida, visando sua autonomia, independência, qualidade de vida e inclusão social (AMORIM et al., 2009, p. 26).

No processo de construção e vivências com os recursos de tecnologia assistiva, o Pedagogo e o Terapeuta Ocupacional podem criar um ambiente que favoreça o envolvimento do escolar em suas ações, permitindo que ele seja sujeito do seu próprio processo de transformação, elaborando a aceitação da deficiência visual, adquirindo autonomia no conhecimento do uso de seu resíduo visual e vivenciando situações que possibilitam independência na execução de suas atividades escolares e cotidianas, a fim de conquistar a melhora na sua qualidade de vida.

Segundo Ferrigno (1990), a Terapia Ocupacional é um processo de tratamento que utiliza a atividade como recurso, possibilitando por meio dela viabilizar a expressão, a espontaneidade, o conhecimento das potencialidades e das limitações dos sujeitos durante 
suas ações. Neste contexto, a terapia ocupacional se apropria dos recursos de tecnologia asssitiva, para favorecer oportunidades na construção de adaptações específicas às pessoas com deficiência visual, adequadas ao seu contexto de vida, como prancha de plano inclinado, assinador, tiposcópio de leitura, pranchas para atividade de escrita, entre outros.

A tecnologia assistiva é uma área do conhecimento e de atuação que desenvolve serviços, recursos e estratégias que auxiliam na resolução de dificuldades funcionais das pessoas com deficiência para a realização de suas tarefas no cotidiano.

No âmbito educacional, a forma como o texto impresso é apresentado, pode limitar a acessibilidade do escolar com deficiência visual e privá-lo da participação nas aulas. A dificuldade encontrada na leitura de materiais impressos deve ser bem avaliada, sendo necessário identificar se ela está, ou não, no formato que atenda às necessidades do escolar (SARTORETTO; BERSCH, 2010). Ao trabalharem com a informática, os professores devem favorecer a participação de todos os alunos, sem discriminação. Devem refletir, além dos aspectos pedagógicos, sobre como favorecer o encontro das habilidades dos diferentes alunos com as características apresentadas pelos variados ambientes computacionais (MELO, 2010).

\section{Recursos de Tecnologia Assistiva Para Escolares com Baixa Visão}

Na atuação com pessoas com deficiência visual é importante saber que existem enor- mes diferenças entre as pessoas com baixa visão e as pessoas cegas, entre a cegueira congêntita e a adquirida e entre a baixa visual congênita e a adquirida (KASTRUP, 2010). Nesta direção pode-se afirmar que os recursos que beneficiam um indivíduo, podem não beneficiciar outro e será por meio de avaliação que eles serão selecionados considerando o nível de acuidade visual e as necessidades individuais.

Tecnologia assistiva para indivíduos com baixa visão é qualquer recurso que propicie o melhor desempenho desta pessoa em suas atividades (FAYE, 1984). Tais recursos foram desenvolvidos para auxiliarem pessoas com baixa visual a realizarem as atividades cotidianas utilizando o resíduo visual e habilidades remanescentes, tendo acesso aos ambientes. Também aumentam a eficiência visual e o conforto para a pessoa com baixa visão utilizar a visão remanescente em atividades específicas com independência e autonomia (WORLD HEALTH ORGANIZATION, 1993).

Tais auxílios podem ser classificados com o recursos ópticos, não ópticos, eletrônicos e de informática. Os recursos ópticos podem ser para perto e para longe e auxiliam na magnificação da imagem e melhoram a visão residual de indiv; iduos com baixa visão. Para longe compreendem os sistemas telescópicos, lupas manuais, de apoio, de mesa, óculos especiais dentre outros, e exigem certo período de adaptação devendo ser usados em situação estática (GASPARETTO, 2008).

Para identificar objetos, imagens e pessoas, os escolares com baixa visão podem fazer uso dos óculos, das lentes de contato e dos sistemas telescópicos que podem ser monoculares ou binoculares que proporcionam a aproximação dos objetos, mas, em contra 
partida reduzem o campo visual. De forma geral, esse recurso é utilizado para a visualização do quadro negro na escola, da televisão, bem como para o reconhecimento de linhas de ônibus, de pessoas, nome de ruas, entre outros (CARVALHO et al., 2002).

Para perto, os recursos ópticos podem ser por meio de lentes montadas em armação de óculos, lupas manuais e as lupas de apoio. As lupas são muito úteis para ampliarem o material de leitura, mapas, gráficos, etc. É importante lembrar que quanto maior o aumento da lupa menor o campo de visão. Com isso há, também, diminuição da velocidade de leitura e conseqüentemente maior fadiga visual (CARVALHO et al., 2002).

As lupas manuais são portáteis, sendo aconselhado o seu uso em leituras curtas, pois é cansativo segurá-las por muito tempo. As lupas de apoio são recomendadas para leituras mais prolongadas, pois a sua base proporciona a distância correta e as mãos ficam mais livres. A seleção de tais auxílios recursos tem como base a baixa visual do sujeito, as necessidades visuais e as atividades cotidianas a serem realizadas e são prescritos por um oftalmologista (GASPARETTO, 2008).

Os escolares com baixa visão podem aprimorar o desempenho da visão residual também por meio do uso de recursos não ópticos, ou seja, recursos que não utilizam lentes. Os recursos não-ópticos são recursos simples que podem ser usados de forma independente ou como complemento dos recursos ópticos. Entre os recursos não ópticos utilizados pelos mesmos destacam-se a ampliação de materiais, o uso de acessórios de suporte a leitura e escrita, cadernos com pautas ampliadas, lápis 6B ou 3B, canetas hidrográficas que permitem maior contraste, livros com le- tras ampliados, iluminação e uso do tiposcópio. Chapéus e bonés podem contribuir para diminuir a reflexão excessiva da luz em ambiente externo (GASPARETTO, 2010).

Dependendo da doença ocular, as pessoas com baixa visão podem necessitar de mais ou menos iluminação. Doenças como a catarata, a retinopatia diabética, por exemplo, requerem iluminação mais intensa para a realização de atividades de leitura e escrita. A condição ideal é que haja um foco luminoso direcionado ao material a ser trabalhado. Caso isso não seja possível, garantir o controle de iluminação na sala, para conseguir a eficiência e conforto visual destas pessoas (GASPARETTO, 2010).

Os escolares com deficiência visual também se beneficiam dos recursos de informática disponíveis que associam interfaces visuais, sonoras e táteis por intermédio de programas específicos com sintetizadores de voz e ampliação que podem ser usados de maneira conjunta ou não. Existem softwares livres, como o DOSVOX e o WINVOX podem ser adquiridos gratuitamente na internet com ampliação além da síntese de voz e privados como o Zoomtext e Magic (OKA; NASSIF, 2010).

A opção de utilizar na informática um recurso visual, tátil ou sonoro vai depender do grau da deficiência visual do indivíduo, do material que será acessado e das preferenciais individuais (MORTI MER, 2010).

O ambiente windows permite uma série de ajustes nas configurações favorecendo adaptações no uso do mouse, teclado, vídeo e som. Na edição de texto há possibilidades de ajuste de zoom, tamanho e tipo de fonte, espaçamento e edição em colunas. Todas estas adaptações são individualizadas, sendo indi- 
cadas de acordo com a necessidade de cada escolar (MORTIMER, 2010).

Para a melhor utilização do resíduo visual e dos recursos de tecnologia assistiva, os escolares com baixa visão são encaminhados para participarem de Programas de Habilitação e Reabilitação Visual, no qual são proporcionadas a apresentação e vivência com os recursos de tecnologia assistiva.

\section{Recursos de Tecnologia Assistiva Para os Escolares Cegos}

No processo de escolarização, o Sistema Braille é o recurso fundamental para a comunicação escrita da pessoa com cegueira. É constituído por 63 sinais formados a partir da combinação de 6 pontos em relevo (OKA; NASSIF, 2010).

Para a escrita do Sistema Braille podem ser utilizados a reglete (uma régua com pontos em Braille perfurados manualmente com uma punção), e a máquina Braille, manual ou elétrica, que possibilita agilidade e rapidez. Por intermédio da impressora Braille são produzidos livros contendo gráficos e ilustrações de ótima qualidade.

As pessoas com cegueira podem também ter acesso à leitura por meio dos displays Braille e das impressoras em Braille. O display Braille é um equipamento eletromecânico que exibe em Braille frases e parte dos textos. As impressoras Brailles funcionam junto com softwares especiais para imprimir textos em Braille e imagens em alto relevo (MORTI MER, 2010).

A complementação curricular para o aluno com cegueira, tem sido feita por meio do So- roban, nome dado ao ábaco japonês de origem chinesa (OKA; NASSIF, 2010).

As representações gráficas realizadas com relevo adaptadas em ilustrações, mapas gráficos, esquemas e maquetes são importantes recursos pedagógicos e podem ser utilizados nas tarefas escolares, como em outras situações. São adaptações artesanais realizadas com cola plástica, fitas adesivas, carretilha de costura, canetas; pranchetas com tela, feltro ou borracha. Podem ser utilizados tecidos, EVA, fios, lixas, papéis, miçangas, botões e outros materiais (OKA; NASSIF, 2010).

As representações também podem ser feitas com carretilhas em folhas de alumínio e outros instrumentos afins sobre uma prancha de borracha. As representações feitas com colagem e em alumínio podem ser reproduzidas em máquinas termoformadas (processo por calor e vácuo) em Oka e Nassif (2010).

Para a realização do desenho de figuras geométricas, podem ser utilizadas pranchas preparadas com diversos materiais: papelão grosso ou eucatex revestidos de tela de naylon que deve estar bem esticada e fixada com fita adesiva no verso da prancha. O papel deve ser preso na prancha com presilhas e sobre ele podem ser feitos desenhos com caneta, lápis, giz de cera, etc. Pode também ser utilizada uma base feita com lençol de borracha, que não seja muito rígida ou muito macia para evitar que se fure na realização do desenho (OKA; NASSIF, 2010).

As pessoas com cegueira podem também ter acesso à leitura por meio dos displays Braille e das impressoras em Braille. O display Braille é um equipamento eletromecânico que exibe em Braille frases e parte dos textos. As impressoras Brailles funcionam em conjunto com softwares especiais para impri- 
mir textos em Braille e imagens em alto relevo (MORTIMER, 2010).

Os recursos de informática também são utilizados para a produção de desenhos. Estes são fundamentais para o estudo, lazer, pesquisa e trabalho, favorecendo a independência e autonomia das pessoas com deficiência visual. O acesso aos softwares ampliados ou sonoros, e à internet promove a pessoa com deficiência visual, incluindo-o na era digital, favorecendo as relações interpessoais, a comunicação independente nas atividades de leitura e escrita além das atividades escolares e profissionais (GASPARETTO et al., 2009).

Considerando que Tecnologia Assistiva (TA) é uma área do conhecimento de característica interdisciplinar, esta publicação tem como objetivo apresentar como os escolares com deficiência visual participaram de ações de reabilitação nos setores de Pedagogia e Terapia Ocupacional por meio do uso de recursos de tecnologia assistiva, e verificar o conhecimento das necessidades desses recursos na escola, a confecção e adaptação dos mesmos.

\section{Sujeito e Método}

Realizou-se um estudo qualitativo e quantitativo. Segundo Fonseca (2002), a utilização conjunta da pesquisa qualitativa e quantitativa permite recolher mais informações do que se poderia conseguir isoladamente.

Esta pesquisa foi aprovada pelo Comitê de Ética em Pesquisa, da Faculdade de Ciências Medicas da Unicamp, sob o no 570/2010, realizada de acordo com as normas da Resolu- ção 196/96 da Comissão Nacional de Ética em Pesquisa (BRASIL, 1996) e foi desenvolvida no Centro de Estudos e Pesquisas em Reabilitação Prof. Dr. Gabriel O. S. Porto (CEPRE).

Participaram do estudo, escolares com deficiência visual participantes dos programas de habilitação e reabilitação e que estavam incluidos em escolas regulares do sistema de ensino público ou privado. A coleta de dados foi durante o ano de 2010 e realizada por meio de um diário de campo para registrar as atividades desenvolvidas pela pedagogia (DESLANDES; GOMES; MINAYO, 2010).

A Terapia Ocupacional elaborou um questionário semi-estruturado que permitiu, por meio de entrevista, verificar as seguintes variáveis: idade, sexo, inserção escolar, necessidades e interesses no uso de tecnologia assistiva, presença de adaptações no ambiente escolar, uso dos recursos e o conhecimento sobre os recursos de tecnologia assistiva.

A partir do conhecimento das necessidades específicas, cada escolar selecionou e confeccionou equipamentos de tecnologia assistiva como: tiposcópio (guia de leitura), plano inclinado, régua adaptada, pautas reforçadas na cor preta e textos com letras ampliadas. Os recursos de adaptação foram construídos com materiais de baixo custo e recicláveis. As confecções dos materiais e respectivas vivências para o uso da TA aconteceram durante os atendimentos da Terapia Ocupacional.

\section{Abordagem Metodológica do Setor de Pedagogia}

Foram organizados grupos de escolares, com o número médio de sete participantes. 
Com cada grupo foram realizados sete encontros, visando o uso da visão residual com os recursos de tecnologia assistiva, por meio de vivências com a informática, com os recursos ópticos e não ópticos em atividades de leitura, escrita e em atividades cotidianas como assistir televisão. Foram investigadas as seguintes variáveis: idade, sexo, acuidade visual, uso de informática, uso de recursos ópticos não ópticos, adaptação dos recursos, leitura, escrita e interação grupal.

Para promoção do uso dos recursos de tecnologia assistiva (informática, lupas, sistema telescópico, óculos, canetas de ponta porosa, régua adaptada folhas com pautas ampliadas, iluminação adequada), o programa se propôs a realizar atividades conforme descrição abaixo.

\subsection{Descrição dos Encontros}

\subsubsection{Primeiro encontro}

Os escolares se apresentaram, identificando e relatando sobre a doença ocular que causou a própria deficiência e sobre suas dificuldades visuais no desempenho das atividades escolares.

\subsubsection{Segundo encontro}

Foram apresentados os recursos ópticos e os recursos não ópticos. A partir das necessidades de cada escolar, os recursos foram escolhidos e iniciadas atividades livres e/ou dirigidas para aperfeiçoarem a funcionalidade visual.

\subsubsection{Terceiro encontro}

Foram disponibilizados textos impressos na fonte arial e com tamanho de fonte adaptado às necessidade individuais, tendo sido utilizados os seguintes tamanhos: 14, 16, 22, 36,42 . Após o término da leitura, o texto era discutido entre todos e eram socializadas as dificuldades existentes.

\subsubsection{Quarto encontro}

Realização de um mural de recados, no qual cada escolar utilizando-se de recursos necessários escrevia uma carta ao colega.

\subsubsection{Quinto encontro}

Foram confeccionados guias de leitura, pautas ampliadas, suporte de leitura e tiposcópio para que os escolares utilizassem tais recursos durante o processo de habilitação/ reabilitação e bem como, em suas residências ou escola.

\subsubsection{Sexto e sétimo encontros}

Foram propiciadas vivências com o recurso da informática por meio do software livre DOSVOX, com utilização da ampliação e da síntese de voz. Foi demonstrado o ambiente do Windows e os recursos de acessibilidade contidos nele e apresentada a lente de aumento do Windows. 


\section{Resultados}

A população estudada pelo setor de Pedagogia foi composta por 13 escolares com baixa visão participantes do Programa de Reabilitação Visual, de ambos os sexos, sendo 08 do sexo masculino e 05 do sexo feminino, com faixa etária entre 12 e 46 anos. Os escolares encontravam-se matriculados no ensino fundamental II, no ensino médio e na EJ A. A acuidade visual variou entre 20/100 a $20 / 400$ e foram classificados nas categorias de visão moderada, grave e profunda.

Verificou-se que a maioria $(54,0 \%)$ dos escolares utilizava recurso óptico, sendo mencionados o uso de lupa manual, de lupa de apoio e dos óculos. Parcela importante de escolares $(46,0 \%)$ ainda não fazia uso dos mesmos, mas declarou interesse em utilizálos (Tabela 1).

TABELA 1 - Utilização de Recursos Òpticos e Não Ópticos na Pedagogia - Programa de Reabilitação Visual 2010

\begin{tabular}{|c|c|c|}
\hline \multicolumn{2}{|c|}{ Uso de recurso óptico } & $\mathrm{n}=13$ \\
\hline & $\mathbf{F}$ & $\%$ \\
\hline Sim & 07 & 54,0 \\
\hline Não & 06 & 46,0 \\
\hline \multicolumn{2}{|c|}{ Tipos de recursos ópticos* } & $\mathrm{n}=07$ \\
\hline & $\mathbf{F}$ & $\%$ \\
\hline $\begin{array}{l}\text { Lupa ma- } \\
\text { nual }\end{array}$ & 01 & 14,2 \\
\hline Óculos & 05 & 71,4 \\
\hline $\begin{array}{l}\text { Lupa de } \\
\text { apoio }\end{array}$ & 02 & 28,5 \\
\hline $\begin{array}{c}\text { Sistema } \\
\text { Telescópico }\end{array}$ & 03 & 42,8 \\
\hline & & \\
\hline & & \\
\hline
\end{tabular}

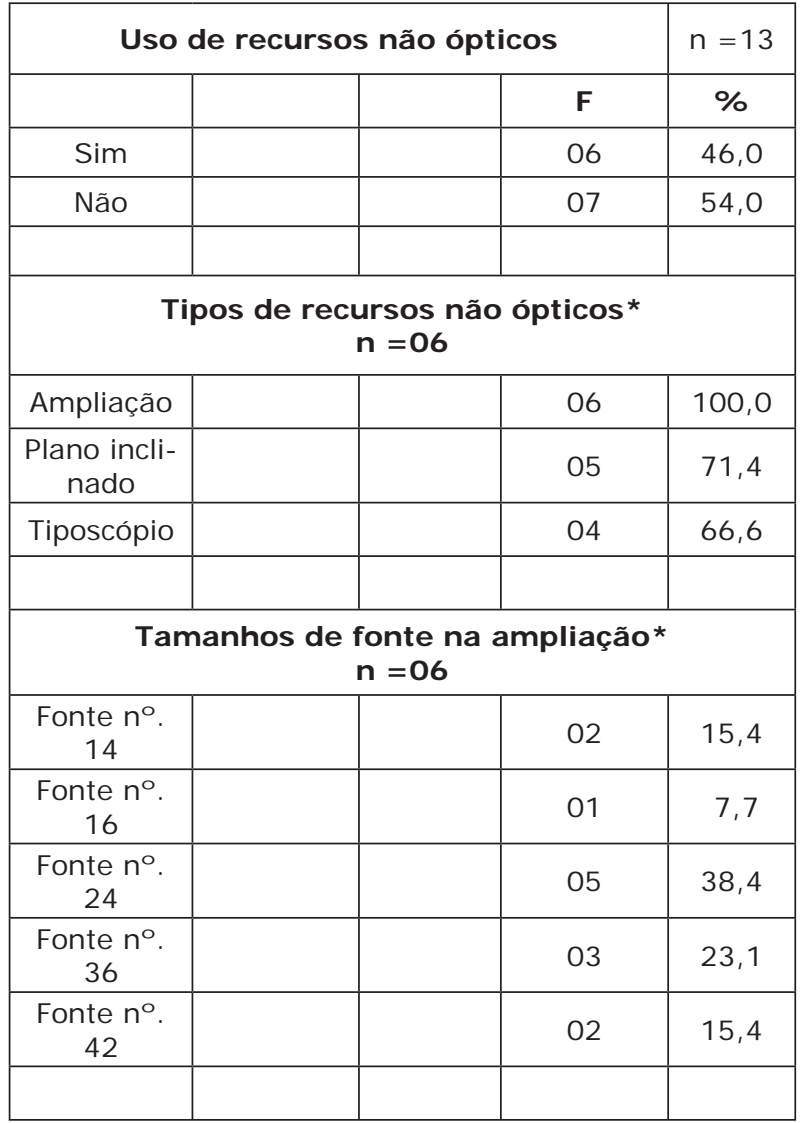

* Respostas múltiplas

Elaborado pela autoras: SPERQUE, J.; ARRUDA, S.M.C.P.; GASPARETTO, M.E.R.F.(2011)

TABELA 2 - Utilização da Informática na Pedagogia: Dosvox e Uso da Lente de Aumento do Windows (Lawindows). Programa de Reabilitação Visual 2010

\begin{tabular}{|c|c|c|}
\hline & & $n=13$ \\
\hline Informática & $\mathbf{F}$ & $\%$ \\
\hline Uso prévio & & \\
\hline Sim & 05 & 38,4 \\
\hline Não & 08 & 61,6 \\
\hline Uso de soft & & $n=07$ \\
\hline Não & 05 & 38,4 \\
\hline Sim & 08 & 61,6 \\
\hline
\end{tabular}




\begin{tabular}{|c|c|c|c|c|}
\hline & & & & \\
\hline Dosvox & & & 03 & 23,1 \\
\hline Lawindows & & & 03 & 23,1 \\
\hline $\begin{array}{c}\text { Dosvox/La- } \\
\text { windows }\end{array}$ & & 02 & 15,4 \\
\hline \multicolumn{4}{|l}{} \\
\hline
\end{tabular}

Elaborado pela autoras: SPERQUE, J.; ARRUDA, S.M.C.P.; GASPARETTO, M.E.R.F.(2011)

Na Tabela 2, os resultados demonstraram que somente $38,4 \%$ dos escolares participantes tinham conhecimento prévio da informática, mas apresentavam desconhecimento em relação aos softwares específicos para a baixa visão e mesmo após terem sido apresentados ao DOSVOX e à Lente de Aumento do Windows, optaram por continuarem a utilizar a informática sem o software específico. Verificou-se que $23,1 \%$ preferiram utilizar o DOSVOX e 23,1\% optaram pelo uso da Lente de Aumento do Windows, enquanto parcela restrita $(15,4 \%)$ optou por utilizar simultaneamente o DOSVOX e a Lente de Aumento.

A população estudada pela Terapia Ocupacional foi composta por 33 indivíduos com deficiência visual, sendo que $60,0 \%$ eram do sexo feminino. A faixa etária dos sujeitos variou entre 7 e 17 anos, com média de idade de 14 anos, sendo todos participantes do Programa de Reabilitação do CEPRE/FCM/ UNICAMP.

Em relação ao conhecimento dos recursos de tecnologia assistiva $70,0 \%$ dos sujeitos relataram não conhecer a utilização e a importância dessas tecnologias. Verificouse que $71,0 \%$ dos entrevistados relataram a ausência desses equipamentos e adaptações no âmbito escolar. Quanto ao interesse dos escolares pela utilização dos recursos de tecnologia assistiva nas atividades escolares, observou-se que $22,0 \%$ teve interesse no uso do plano inclinado, seguido pelo uso das pautas e fontes ampliadas 19,0\%, Braille móvel $15,0 \%$, régua adaptada $14,0 \%$, prancha de alfabetos e números em Braille 12,0\% e tiposcópio 8,0\%.

\section{Discussão}

A habilitação e a reabilitação visual de escolares com deficiência visual está situada no universo das diferenças, e é somente por meio da convivência com a multiplicidade que se aprende a conviver, respeitar, valorizar e aprender com os diferentes. Conforme Ropoli et al. (2010) as diferenças decorrem da multiplicidade e não da diversidade, como comumente se proclama.

A sociedade inclusiva concebe a educação inclusiva como um espaço de todos, no qual os escolares constroem conhecimentos segundo suas capacidades, expressam sua idéias livremente, participam ativamente das atividades escolares, e se desenvolvem como cidadãos, nas suas diferenças.

Como filosofia de habilitação e reabilitação da pessoa com deficiência visual, os profissionais do CEPRE têm o papel de instrumentalizadores e facilitadores no processo de crescimento e desenvolvimento do próprio sujeito. Montilha (2006, p. 10) relata que deve se considerar e respeitar a história de vida, o estilo cognitivo, as expectativas, as resistências emocionais, o potencial, as habilidades e o ritmo tanto da família quanto do próprio sujeito, durante o processo de reabilitação. Enfatiza que o conhecimento das per- 
cepções de escolares com deficiência visual a respeito de seu processo de escolarização é fundamental ao planejamento de ações educativas (MONTI LHA et al., 2009).

O indivíduo com baixa visão ou cegueira pode se beneficiar de adaptações diversas que permitam um melhor uso funcional da sua visão e ou de outras habilidades. As sugestões dessas adaptações devem ser propostas por terapeutas ocupacionais ou profissionais especializados, após um trabalho intenso de observação e conhecimento das necessidades específicas dessas pessoas (SOLER; PLAZZA; EZEQUIEL, 2007).

A análise dos resultados indica que a maioria dos respondentes $(70,0 \%)$ desconhecem e não utilizam a tecnologia assistiva no âmbito escolar. Crianças e adolescentes com deficiência visual deveriam utilizar recursos de tecnologia assistiva na realização das atividades escolares. Para Monteiro et al. (2006) a necessidade de aceitação social e o desejo de fazer parte de um grupo, de escolares jovens, constituem-se em barreiras na utilização desses recursos. Por outro lado, a falta de informação por parte dos profissionais do sistema educacional pode impedir a correta utilização dessas tecnologias. Estudos mostram que escolares com deficiência visual encontram muitas vezes dificuldades no processo escolar devido à insuficiência de recursos apropriados (GASPARETTO et al., 2001).

Somente na perspectiva de acolher as diferenças e promover novas práticas que levem a melhores perspectivas de vida é que os profissionais têm condições de oferecer diferentes formas de utilização do resíduo visual e de suas habilidades para que esse escolares não fiquem excluídos de organizarem o seu ambiente por meio de informações visuais.
Cabe aos profissionais da reabilitação mostrarem aos escolares e seus professores formas de modificar o ambiente, como por exemplo, aproximarem-se da lousa, melhorar a iluminação, posicionar o aluno na primeira fileira, colocando-o na carteira central, entre outros. Além disso, esses profissionais poderiam apresentar e favorecer vivências com o uso de recursos e de adaptações, quando necessários.

A dimensão psicossocial da deficiência visual implica em crenças que foram construídas devido ao desconhecimento, pois a prática antiga era conservadora em termos do uso da visão residual. Era enfatizada a economia da visão pelo uso do sistema Braille e de materiais táteis e tal crença, presente nos dias atuais, faz com que as pessoas com baixa visão, fiquem resistentes ao uso da visão residual com ou sem auxílios ópticos.

Ponderando os relatos sobre as queixas acadêmicas dos escolares com baixa visão, verifica-se a necessidade do trabalhar a visão residual nas atividades de leitura e escrita, de forma gradativa, selecionando estratégias dinâmicas e interativas para a sua efetivação, considerando que o reconhecimento de frases requer a utilização de uma área maior na retina. Para cumprir essa etapa pode ser útil solicitar que o escolar comece a ler impressos com tipos ampliados, para que possam ler mais facilmente e a leitura se torne mais interessante e menos cansativa.

Pesquisas têm mostrado que o aproveitamento acadêmico de escolares com deficiência visual, é equivalente ao dos alunos que tem visão normal e como qualquer estudante, podem apresentar dificuldades na realização das atividades acadêmicas, mas que em princípio nada estaria relacionado a 
problemas de natureza cognitiva. Decorrente disso, é importante compreender como cada escolar com deficiência visual se organiza e saber o que exatamente ele consegue fazer é de extrema importância para o bom desempenho escolar (LAVARDA; BIDARRA, 2007).

$\mathrm{Na}$ habilitação/reabilitação de escolares com deficiência visual, é importante que os profissionais promovam o desenvolvimento de habilidades e, nos casos de baixa visão favoreçam o uso da visão residual por meio do uso de recursos de tecnologia assistiva promovendo o acesso à leitura e à escrita de forma a interagirem com outros escolares, mostrando que na utilização de diferentes estratégias, a linguagem escrita pode e deve fazer parte de seu cotidiano.

Resultados da pesquisa realizada por Montilha, em 1997, demonstraram que 80,0\% dos participantes de um grupo de reabilitação desejavam desenvolver a utilização do resíduo visual, 64,0\% desejavam realizar atividades de leitura e escrita, e 40,0\% desejavam utilizar os recursos prescritos.

O processo de habilitação/reabilitação visa auxiliar o escolar com deficiência visual em atividades rotineiras, nas quais encontra dificuldade em realizar. Segundo Montilha (2000) estes processos devem favorecer a expressão de sentimentos, a espontaneidade, o conhecimento das potencialidades e limitações e o desenvolvimento e aprimoramento de habilidades. As atividades desenvolvidas podem ser expressivas, pedagógicas, lúdicas, de automanutenção e profissionalizantes. No programa de habilitação/reabilitação visual ou na escola, os recursos não ópticos podem ser utilizados isoladamente ou em conjunto com os recursos ópticos. De forma geral, os recursos: braille móvel, prancha de alfabetos, e números em braille, são utilizados por pessoas com cegueira. Já o tiposcópio, o plano inclinado, pautas e fontes ampliadas são mais utilizados por escolares com baixa visão. A régua adaptada e outros recursos podem ser utilizados tanto por escolares cegos quanto com baixa visão.

Em relação ao uso dos recursos de informática, a maioria $(61,6 \%)$ dos escolares ainda não havia utilizado tal recurso e relata ter adquirido conhecimento e informações no Programa de Reabilitação. Dos escolares $(38,4 \%)$ que relataram o uso prévio da informática, todos referiram o desconhecimento de softwares específicos como os sintetizadores de voz Dosvox e os recursos do Windows e preferiram a não utilização destes, mesmo após a apresentação.

Em pesquisa realizada para verificar o uso e disponibilidade de recursos de tecnologia assistiva em instituições de educação municipal, estadual e federal tecnológica observouse que, os recursos e equipamentos destinados a escolares com deficiência visual não estão chegando às escolas e os professores também relataram total desconhecimento, principalmente quanto ao uso de recursos e equipamentos de informática específicos para escolares com deficiência visual (GASPARETTO et al., 2009).

A pesquisa Assistive Technology Applied to Education of Visually Impaired Students, demonstrou que a maioria dos professores $(94,8 \%)$ afirmou não usar a informática com os escolares com deficiência visual. Apresentaram como justificativas: que não é previsto no planejamento das aulas o uso da informática, ausência de programas específicos para pessoas com deficiência visual, a não disponibilização da direção da escola para que 
alunos e professores utilizem o computador, o fato de que o escolar com deficiência visual não saber usar o computador e a crença de que a deficiência não permite usar computadores. Cabe ressaltar que a maioria dos professores também declarou não utilizar tais recursos com os escolares que apresentam visão normal (ALVES et al., 2009).

Entre os participantes entrevistados pela Terapia Ocupacional não houve interesse no conhecimento e aprendizagem da informática, o que traz à reflexão sobre as dificuldades de aquisição, acesso e uso dos equipamentos de informática no domicílio e até mesmo em algumas escolas, que ainda não contam com esses recursos. Foi demonstrado pelos escolares com cegueira interesse por outros recursos de TA, como o braille móvel, prancha de alfabeto em braille.

Tais recursos se destacaram pois atualmente, com a crescente preocupação com a acessibilidade e inclusão, vem ocorrendo uma divulgação maior no uso do braille na vida cotidiana, como na identificação nos caixas eletrônicos de bancos, a sinalização dos elevadores, nas embalagens de produtos, cardápios, etc. (OKA; NASSIF, 2010).

Estudos realizados por Sartoretto e Bersch (2010), relatam que as barreiras de acesso para alguns alunos se dá em razão da forma ou da mídia, no qual o texto é rotineiramente apresentado na escola: livros, textos impressos, textos exibidos pela tela do computador, textos escritos no quadro, cadernos dos colegas, entre outros.

A informática é um importante recurso para o processo de ensino-aprendizagem e a aquisição dos conhecimentos, pois, coloca todas as pessoas em situação de igualdade e contribui para que o escolar com deficiência visual tenha as mesmas oportunidades que o colega que apresenta visão normal. A associação da informática aos recursos de Tecnologia Assistiva juntamente com o sistema Braille, recursos ópticos e não ópticos propicia maior motivação e agilidade à escolarização da pessoa com deficiência visual (ALVES, 2007).

Para as pessoas com deficiência visual o recurso da informática permite transpor as barreiras que limitam a sua comunicação e seu desenvolvimento. Este recurso agiliza a escrita e auxilia a superar grande parte das dificuldades encontradas nessa área. Isto se dá por meio da utilização de softwares leitores de tela e sintetizadores de voz, favorecendo além da leitura de textos e jornais eletrônicos, a comunicação por e-mails, chats, blogs, twiter, sites de busca, biblioteca aberta, livro eletrônico etc., além da educação a distância.

\section{Considerações Finais}

Os setores de Pedagogia e Terapia Ocupacional promoveram o conhecimento de recursos facilitadores e acessíveis à comunicação escrita, bem como a construção e a adaptação de materiais utilizados para serem utilizados nas atividades cotidianas. Promoveram também a utilização da visão residual dos escolares com baixa visão, por meio do uso de recursos de tecnologia assistiva nas atividades propostas.

Foi demonstrada grande satisfação por parte dos indivíduos com deficiência visual ao utilizarem os recursos de tecnologia assistiva, não somente durante os atendimentos dos setores de Pedagogia e Terapia Ocupa- 
cional, mas também nos demais. Houve troca de experiências e vivências entre os participantes, que resultou na melhoria do uso da visão residual.

O aprendizado adquirido e as informações que foram socializadas no grupo de habilitação e reabilitação foram primordiais para a conquista da independência propiciando a vivência com os recursos de tecnologia assistiva e a aplicação desses na vida acadêmica.

Para o melhor desempenho dos escolares com deficiência visual nas atividades acadêmicas é importante que os conteúdos sejam apresentados em formato acessível, por meio de equipamentos e tecnologia adequados às necessidades individuais, para que esses desenvolvam seu potencial e superem possíveis limitações impostas pela deficiência visual. Dessa forma, assegura-se o direito de acesso dos escolares com deficiência visual ao conhecimento assim como aos demais alunos.

Por meio das apresentações e vivências com os recursos de tecnologia assistiva com- provou-se o interesse dos escolares no uso desses recursos nas atividades escolares e no cotidiano.

Verifica-se por meio da literatura que os serviços de reabilitação especializados é que estão propiciando aos escolares com deficiência visual o acesso à informática com softwares específicos e aos outros recursos de tecnologia assistiva. Considerando que as escolas regulares, de forma geral, possuem laboratórios de informática, esse espaço poderia ser o local de primeiro acesso dos escolares a esse recurso.

Os resultados deste estudo poderão subsidiar novas pesquisas que viabilizem aos escolares com deficiência visual a utilização dos recursos de tecnologia assistiva, considerando que tais recursos são agentes que irão propiciar o acesso às informações, melhor desempenho na aprendizagem, na realização das tarefas escolares e das atividades cotidianas, favorecendo a inclusão educacional e social destes indivíduos.

\section{Referências}

ALVES, C.C.F. Uso de Recursos de Informática na Educação de Escolares Deficientes Visuais: conhecimento, opiniões e práticas de professores. 2007. (Dissertação) - Programa de Pós Graduação em Ciências Médicas, Universidade Estadual de Campinas, 2007, Campinas, BR-SP.

ALVES, C.C.F. et al. Assistive Technology Applied to Education of Students with Visual Impairment, 08/2009. Pan American Journal of Public Health, Washington, DC, v. 26, n. 2, p. 148-152, 2009.

AMORIM, A. et al. Comissão Temática 1. Conceituação e Estudo de Normas. In: BRASIL. Subsecretaria Nacional de Promoção dos Direitos da Pessoa com Deficiência. Comitê de Ajudas Técnicas. Tecnologia Assistiva. Brasília: CORDE, 2009. p.13-39. 
BRASIL. Decreto n. 7612, de 17 de novembro de 2011. Institui o Plano Nacional da Pessoa com Deficiência - Plano Viver sem Limite. Diário Oficial [da República Federativa do Brasil], Brasília, DF, 18 nov. 2011. P. 2.

BRASIL. Ministério da Educação e Cultura. Brasília, 2009. Disponível em: <portal.mec.gov.br/index> Acesso em: 15 jul. 2011 .

BRASIL. Ministério da Saúde. Sistema Nacional de Informações Sobre Ética em Pesquisa Envolvendo Seres Humanos. Resolução n. 196, de 10 de outubro de 1996. Aprova as diretrizes e normas regulamentadoras de pesquisas envolvendo seres humanos. Brasília, 1996.

CAIADO, K.R.M. O Trabalho Pedagógico com o Aluno Cego. In: ALUNO Deficiente Visual na Escola. Campinas: Autores Associados, 2003.

CARVALHO, K.M.M et al. Orientações ao Professor do Ensino Regular. 3. ed. Campinas: UNICAMP, 2002.

DESLANDES, S.F.; GOMES, R.; MINAYO, M.C.S. (Org.). Pesquisa Social: teoria, método e criatividade. 29. ed. Petrópolis: Vozes, 2010.

FAYE, E.E. Clinical Low Vision. 2. Ed. Boston: Litle, Brown and Company, 1984.

FERRIGNO, I.S.V. Um Estudo Sobre os Docentes de Terapia Ocupacional Como Agentes Transformadores da Profissão. 1990. Dissertação (Mestrado em Psicologia Social) - Pontifícia Universidade Católica de São Paulo, 1990, São Paulo, BR-SP.

FONSECA, J.J.S. Metodologia da Pesquisa Científica. Fortaleza: UEC, 2002.

GASPARETTO, M.E.R.F. Família e Escola: atenção à baixa visão. In: SOUZA, O.S.H. (Org.). Itinerários da Inclusão Escolar. Porto Alegre: Ulbra, 2008. P.33-41.

GASPARETTO, M.E.R.F. Orientações ao Professor e à Comunidade Escolar Referentes ao Aluno com Baixa Visão. In: SAMPAIO, M.W. et al. Baixa Visão e Cegueira: os caminhos para a reabilitação, a educação e a inclusão. Rio de Janeiro: Cultura Médica; Guanabara Koogan, 2010. P. 347-360.

GASPARETTO, M.E.R.F. et al. O Aluno Portador de Visão Subnormal na Escola Regular: desafio para o professor? Arquivos Brasileiros de Oftalmologia, São Paulo, v. 64, n. 1, p. 45-51, 2001.

GASPARETTO, M.E.R.F. et al. Uso de Recursos e Equipamentos de Tecnologia Assistiva na Educação Municipal, Estadual e Federal Tecnológica. In: BRASIL. Subsecretaria Nacional de Promoção dos Direitos da Pessoa com Deficiência. Comitê de Ajudas Técnicas. Tecnologia Assistiva. Brasília: CORDE, 2009. P. 41-58. 
IBGE. Censo Demográfico 2010. Brasília, 2010. Disponível em: http://www.ibge.gov.br> acesso em: 05 abr. 2012.

KASTRUP, V. Experiência Estética Para uma Aprendizagem Inventiva: notas sobre a acessibilidade de pessoas cegas a museus. Informatica na Educação: teoria e prática, Porto Alegre, v. 13, n. 2, p. 38-45, 2010.

LAVARDA, S.T.F.; BIDARRA, J. A Dêixis Como um "Complicador/Facilitador" no Contexto Cognitivo e Lingüístico em Ambiente Educacional Face aos Alunos com Deficiência Visual. Revista Brasileira de Educação Especial, Marília, v. 13, n. 3, p. 309-324, 2007.

LIMA, N.M. (Comp.). Legislação Federal Básica na Área da Pessoa Portadora de Deficiência. Brasília: Secretaria Especial dos Direitos Humanos, Coordenadoria Nacional para Integração da Pessoa Portadora de Deficiência, 2007.

MELO, A.M. Informática Acessível nas Atividades Escolares. In: MELO, A.M.; PUPO, D.T. A Educação Especial na Perspectiva da Inclusão Escolar: livro acessível em informática acessível. Brasília: Ministério da Educação, Secretaria de Educação Especial; Fortaleza: Universidade Federal do Ceará, 2010. (Coleção A Educação Especial na Perspectiva da Inclusão Escolar, v. 8) P. 18-41.

MONTEIRO, G.B.M.; TEMPORINI, E.R.; CARVALHO, K.M. Use of Optical Aids by Visually Impaired Students: social and cultural factors. Arquivos Brasileiros de Oftalmologia, São Paulo, v. 69, n. 4, p. 503, jul./ago. 2006.

MONTILHA, R.C.I. Reabilitação de Portadores de Deficiência Visual: características, conhecimentos e opiniões de clientela atendida em um Centro Universitário. 1997. Dissertação (Mestrado) - Faculdade de Ciências Médicas, Universidade Estadual de Campinas, 1997, Campinas, BR-SP.

MONTILHA, R.C.I. et al. Deficiência Visual: características e expectativas da clientela de serviço de reabilitação. Revista de Ciências Médicas, Campinas, v. 9, n. 3, p. 123-128, 2000.

MONTILHA R.C.I. et al. Utilização de Recursos Ópticos e Equipamentos por Escolares com Deficiência Visual. Arquivos Brasileiros de Oftalmologia, São Paulo, v. 69, n. 2, p. 207-211, 2006.

MONTILHA, R.C.I. et al. Percepções de Escolares com Deficiência Visual em Relação ao Seu Processo de Escolarização. Revista Paidéia, Ribeirão Preto, v. 19, n. 44, p. 333-339, set./dez. 2009.

MORTIMER, R. Recursos de Informática Para a Pessoa com Deficiência Visual. In: SAMPAIO, M.W. et al. Baixa Visão e Cegueira: os caminhos para a reabilitação, a educação e à inclusão. Rio de Janeiro: Cultura Médica; Guanabara Koogan, 2010. P. 221-234. 
OKA, M.C.; NASSIF, M.C.M. Recursos Escolares Para o Aluno com Cegueira. In: SAMPAIO, M.W. et al. Baixa Visão e Cegueira: os caminhos para a reabilitação, a educação e à inclusão. Rio de J aneiro: Cultura Médica; Guanabara Koogan, 2010. P. 389-414.

ROPOLI, E.A. et al. A Educação Especial na Perspectiva da Inclusão Escolar: a escola comum inclusiva. Brasília: Ministério da Educação, Secretaria de Educação Especial; [Fortaleza]: Universidade Federal do Ceará, 2010. (Coleção A Educação Especial na Perspectiva da Inclusão Escolar, v. 1)

ORGANIZAÇÃO MUNDIAL DA SAÚDE. Classificação Internacional de Doenças e Problemas Relacionados à Saúde. 10. Revisão. São Paulo: Edusp, 1993.

SARTORETTO, M.L.; BERSCH, R.C.R. A Educação Especial na Perspectiva da Inclusão Escolar: recursos pedagógicos acessíveis e comunicação aumentativa e alternativa. Brasília: Ministério da Educação, Secretaria de Educação Especial; [Fortaleza]: Universidade Federal do Ceará, 2010. (Coleção A Educação Especial na Perspectiva da Inclusão Escolar, v. 6)

SOLLER, T.R.F.; PLAZZA, T.G.; EZEQUIEL, L.A. Formação Requerida Para o Professor Especializado Atender o Aluno com Visão Subnormal na Escola Regular. In: MASINI, E.F.S.; GASPARETTO, M.E.R.F. (Org.). Visão Subnormal: um enfoque educacional. São Paulo: Vetor, 2007. P. 55-62.

UNESCO. Declaração de Salamanca e Enquadramento da Ação na Área das Necessidades Educativas Especiais. Salamanca: Unesco, 1994.

VYGOTSKY, L.S. A Construção do Pensamento e da Linguagem. São Paulo: Martins Fontes, 2003.

WORLD HEALTH ORGANIZATION. Management of Low Vision in Children. In: WHO Consultation. Bangkok, 1993. (WHO PBL93.27) 


\section{Maria Elisabete Rodrigues Freire Gasparetto}

Professora Doutora da Universidade Estadual de Campinas, docente e pesquisadora do Depto Desenvolvimento Humano e Reabilitação e do Programa de Pós Graduação Saúde, Interdisciplinaridade e Reabilitação da Faculdade de Ciências Médicas. Campinas/SP, Brasil. E-mail: gasparetto@fcm.unicamp.br

\section{Rita de Cássia letto Montilha}

Professora Doutora da Universidade Estadual de Campinas, docente e pesquisadora do Depto Desenvolvimento Humano e Reabilitação e do Programa de Pós Graduação Saúde, Interdisciplinaridade e Reabilitação da Faculdade de Ciências Médicas. Campinas/SP, Brasil. E-mail: rcietto@fcm.unicamp.br

\section{Sonia Maria Chadi de Paula Arruda}

Professora Doutora da Universidade Estadual de Campinas, docente e pesquisadora do Depto Desenvolvimento Humano e Reabilitação da Faculdade de Ciências Médicas. Campinas/SP, Brasil. E-mail: sonia.arruda@terra.com.br

\section{J acqueline Sperque}

Aprimoranda da Universidade Estadual de Campinas, no Programa de Aprimoramento Profissional em Reabilitação da Saúde Ocular, da Faculdade de Ciências Médicas, no período entre março de 2010 a fevereiro de 2011. Campinas/SP, Brasil. E-mail: jaquelinesperque@ymail.com

\section{Tássia Lopes de Azevedo}

Aprimoranda da Universidade Estadual de Campinas, no Programa de Aprimoramento Profissional em Terapia Ocupacional e Reabilitação, da Faculdade de Ciências Médicas, no período entre março de 2010 a fevereiro de 2011. Campinas/ SP, Brasil. E-mail: tassia_puccamp@yahoo.com.br

\section{Maria I nes Rubo Souza Nobre}

Professora Doutora da Universidade Estadual de Campinas, docente e pesquisadora do Depto Desenvolvimento Humano e Reabilitação e do Programa de Pós Graduação Saúde, Interdisciplinaridade e Reabilitação da Faculdade de Ciências Médicas. Campinas/SP, Brasil. E-mail: inesnobre@fcm.unicamp.br 